\title{
Erythropoietic porphyrin hepatitis
}

\author{
H. D. BARNES, E. HURWORTH, AND J. H. D. MILLAR \\ From the Department of Chemical Pathology, St. Mary's Hospital, London, and Department of Pathology, \\ War Memorial Hospital, Scunthorpe, Lincs.
}

SYNOPSIS The clinical history, laboratory, and necropsy findings in a patient with terminal jaundice and disordered porphyrin metabolism are presented. A retrospective diagnosis of erythropoietic protoporphyria is considered.

J.W.E.F., a man aged 42 years, was first seen in January 1964, complaining of upper abdominal pain of six weeks' duration.

He gave a history of sensitivity to ultraviolet light from the age of 18 years, or possibly even from 10 months of age. On medical advice he had taken chloroquine for two years, without any definite response. Exposure to sunlight or cold winds caused subjective discomfort and resulted in localized flushing if prolonged; the affected areas became warm to the touch. Outdoor activities were precluded. Spontaneous blistering was not noted but cuts or scratches often left depressed scars on healing. None of many local treatments gave any relief but the sensitivity seemed to be diminished for about two years following 'deep $x$-ray treatment' when he was 37 or 38 years old.

On examination, although he appeared well and there was no evidence of jaundice, the liver was enlarged with a smooth, regular outline.

No excess of porphyrin or porphobilinogen was detected in the urine but screening tests showed a gross excess of faecal porphyrin. Serum bilirubin was $3.4 \mathrm{mg}$ / $100 \mathrm{ml}$ and the direct van den Bergh reaction was weakly positive; thymol turbidity and zinc sulphate tests were 6 and 8 units respectively and alkaline phosphatase 15 units.

The hepatomegaly continued and after a few days the patient became jaundiced. As the diagnosis was in doubt a laparotomy was carried out which revealed a hard, almost black liver. Section showed zonal necrosis with regeneration at the periphery of the nodules, a fine perilobular fibrosis (Fig. 1) with a marked inflammatory reaction, together with reduplication of the bile ducts (Fig. 2). The infiltrate consisted mainly of mononuclear cells with some polymorphs and eosinophils. There was intense mahogany brown pigment present and staining reactions excluded similar coloured pigments other than porphyrins (Figs. 3 and 4). Examination in ultraviolet light showed fluorescence attributable to porphyrin, and a histological diagnosis of pigmentary cirrhosis due to porphyria hepatica was made.

The patient was treated with prednisolone but jaundice continued to deepen throughout a rapid downhill course to death on 9 March 1964.

Received for publication 20 July 1967
At post-mortem examination 24 hours later, varices were observed at the lower end of the oesophagus; the stomach and small intestine contained black, bloodstained fluid. The liver weighed $2,170 \mathrm{~g}$, was black, stony hard, and nodular. The spleen was enlarged and tough. Abdominal lymph nodes were increased in size, black, and on histological examination showed increased fibrous tissue, a chronic inflammatory infiltration and intense intra- and extracellular pigment deposition, aggregated to massive clumps at the periphery (Figs. 5, 6).

Analysis of material obtained at necropsy gave the following results: ${ }^{1}$

\begin{tabular}{lcc} 
Specimen & Coproporphyrin & \multicolumn{1}{c}{ Protoporphyrin } \\
\hline $\begin{array}{l}\text { Stool } \\
\text { Urine }\end{array}$ & $31(\mu \mathrm{g} / \mathrm{g}$ dry wt) & $515(\mu \mathrm{g} / \mathrm{g}$ dry wt) \\
$\begin{array}{l}\text { Liver } \\
\text { Bile }\end{array}$ & $940(\mu \mathrm{g} / \mathrm{l})$ & $4,900(\mu \mathrm{g} / \mathrm{g}$ wet wt) \\
& $15(\mu \mathrm{g} / \mathrm{g})$ & $100(\mu \mathrm{g} / \mathrm{g})$
\end{tabular}

Smears of bone marrow made from formol-fixed and unfixed portions of sternum showed considerable flourescence in ultraviolet light.

The ether-soluble porphyrins from stool and liver were fractioned by counter-current analysis (French, England, Lines, and Thonger, 1964). This indicated that the former was very largely protoporphyrin with small amounts of pempto-, deutero- and coproporphyrin. These minor fractions were not detected in the pigment from the liver.

\section{DISCUSSION}

It is unfortunate that blood from this patient was never examined for porphyrins during life, but the cutaneous reactions on exposure and the biochemical findings reported are all compatible with a diagnosis of erythropoietic protoporphyria. Since there is evidence that this condition follows the Mendelian dominant rule of inheritance (Haeger-Aronsen, 1962; Redeker and Bryan, 1964; and Gajdos, Canet, Combrisson, and Gajdos-Torok, 1964) a search for other cases in the family was suggested. An extensive family tree was constructed; though

'The 'uroporphyrin' extract did not show a peak in the Soret region. 


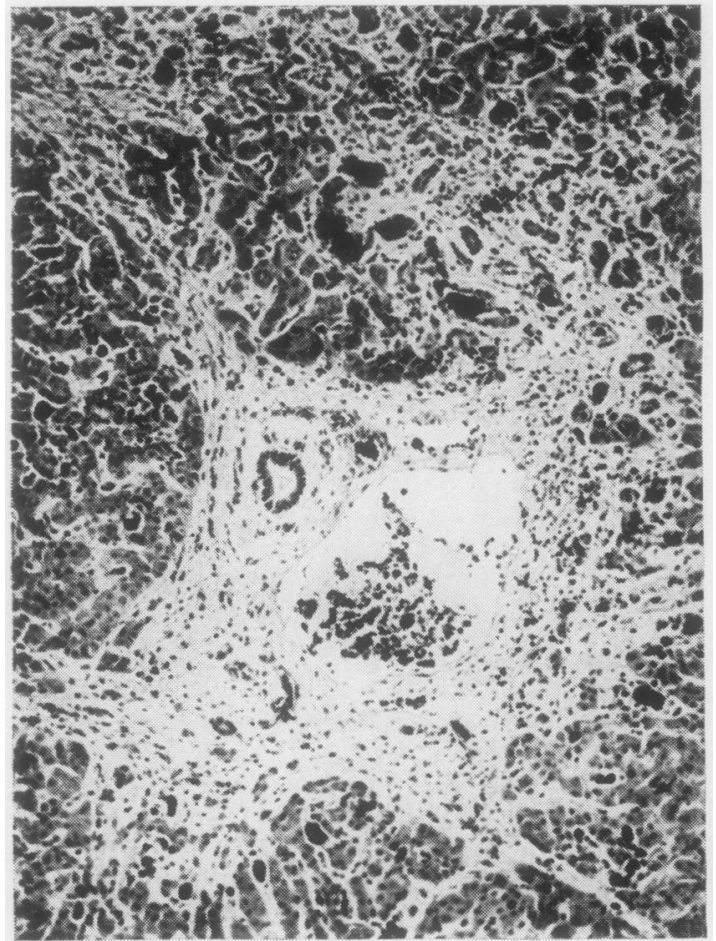

FIG. 1

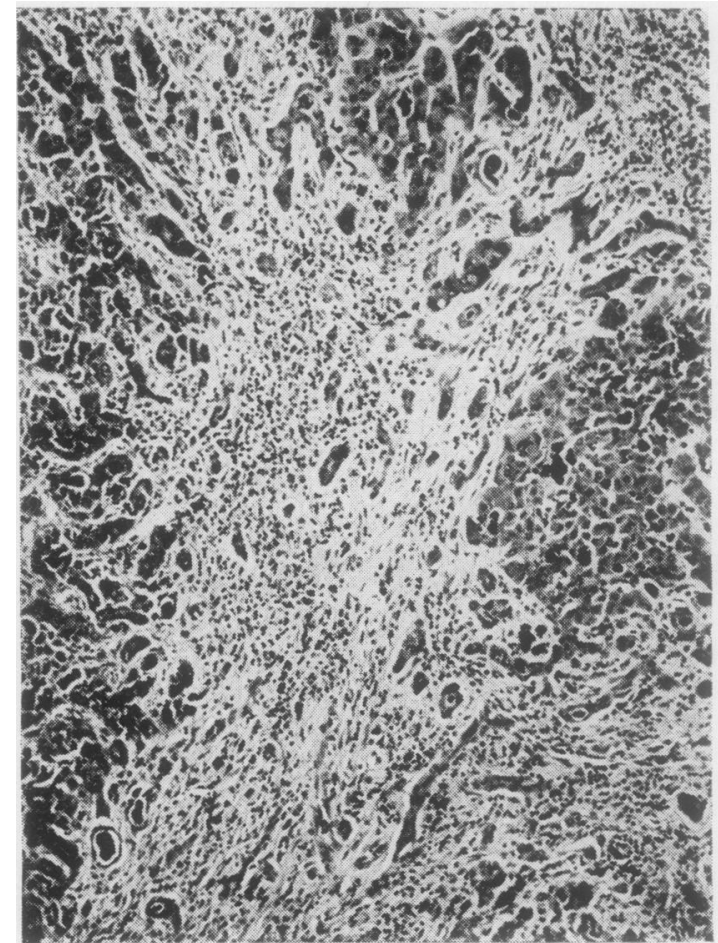

FIG. 2

FIGS. 1 and 2. Fibrosis, bile duct proliferation, and lymphocytic infiltration of portal tracts.

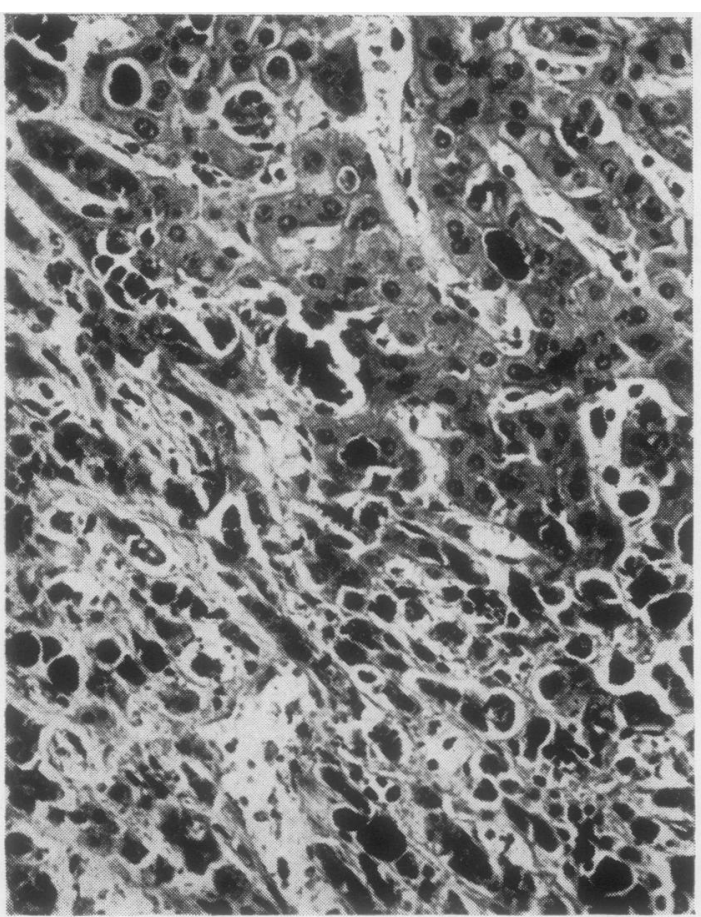

ro. 3

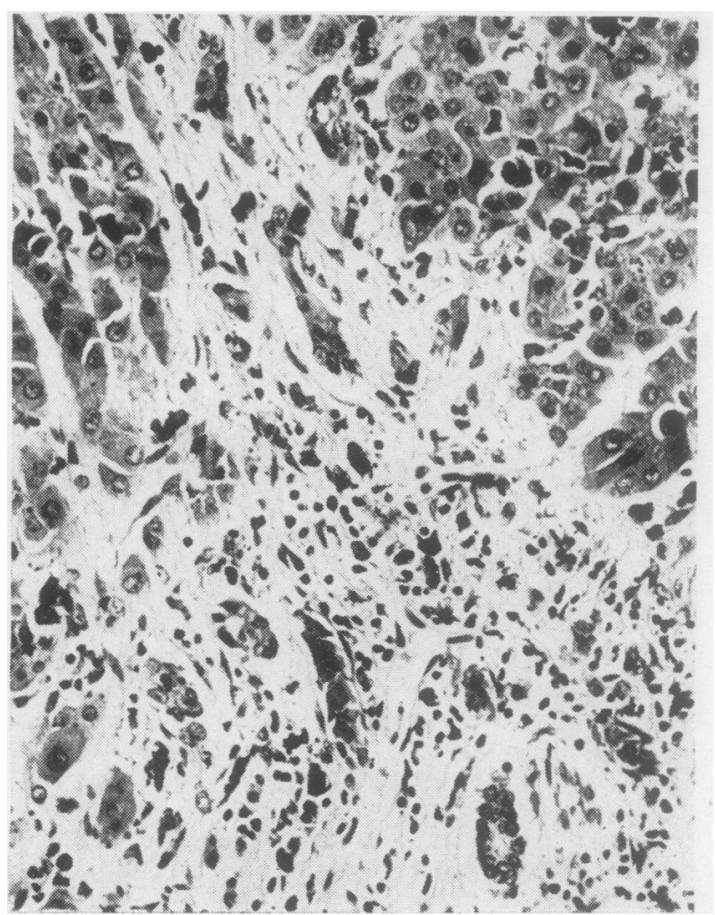

FIG. 4 


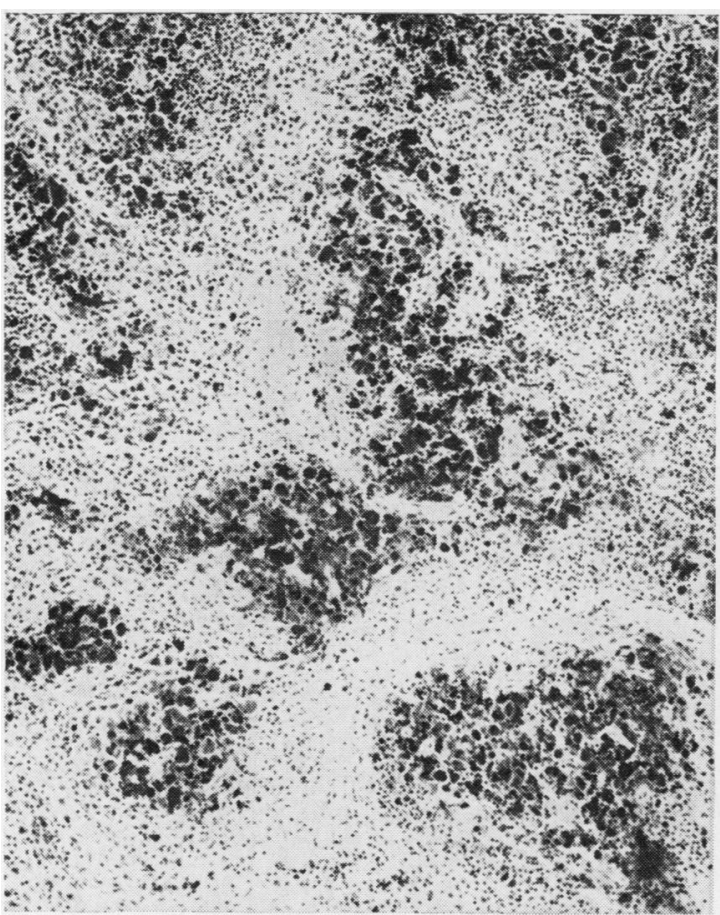

FIG. 5

FIG. 5. Pigmented part of gland.

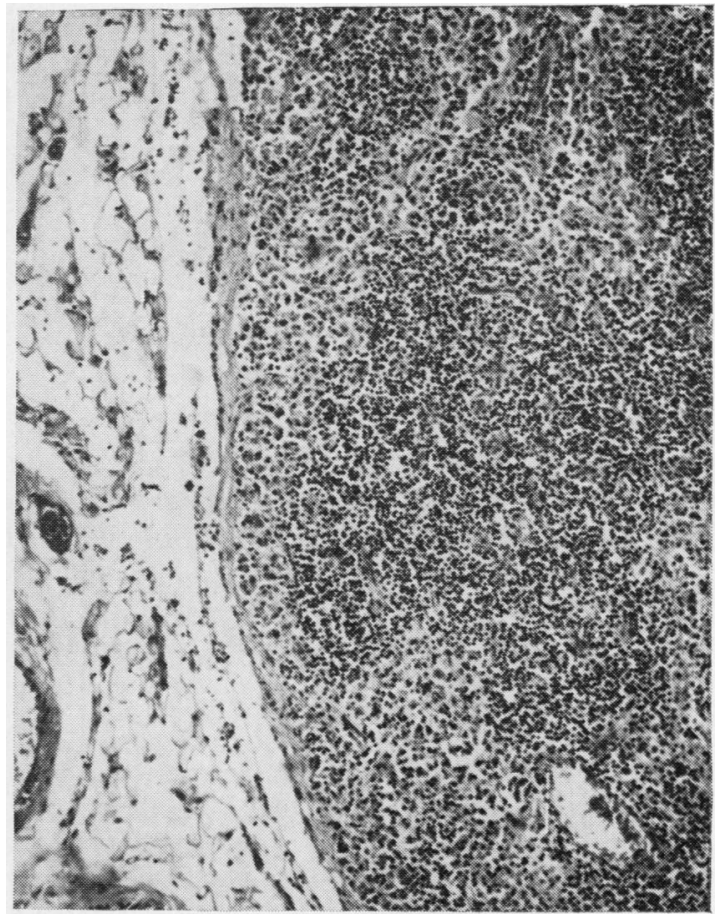

FIG. 6 'sensitive skins' were imputed to several near relations no convincing clinical history was forthcoming from any member. Blood and excreta from several, including the mother, were examined, all with negative results. The father refused to cooperate although said to have a sensitive skin. However, the clinical histories and biochemical findings were negative for both parents of the cases reported by Porter and Lowe (1963) and Harber, Fleischer, and Baer (1964) and the very slight increase of protoporphyrin in the stool from the mother of the cases reported by Holti, Magnus, and Rimington (1963) is inconclusive.

Some patients with erythropoietic protoporphyria do not excrete excessive amounts of protoporphyrin in stools (Redeker and Berke, 1962); HaegerAronsen, 1963), and increased stool porphyrin with normal levels in the erythrocytes has also been recorded. The porphyrin content of the stool is sometimes markedly increased by bacterial degradation of haem pigments and it must be conceded that this might explain the stool findings in our patient because of the oesophageal varices. Screening tests on blood (Rimington and Cripps, 1965) are recommended in cases similar to this.
Though incomplete in some respects this account is published because the condition has so recently been described and also because porphyrin hepatitis is not usually considered in the differential diagnosis of a patient presenting with hepatic enlargement followed by increasing jaundice.

We are grateful to Mr. M. Horwich who did the liver biopsy, to Dr. A. Jordan for the earlier tests for porphyrins in excreta and liver, and to Professor D. M. Pryce for the photomicrographs. H. D. Barnes was in receipt of a personal grant from the Medical Research Council and given laboratory facilities by Professor A. Neuberger, F.R.S.

\section{REFERENCES}

French, J. M., England, M. T., Lines, J., and Thonger, E. (1964). Arch. Biochem., 107, 404.

Gajdos, A., Canet, J., Combrisson, A., and Gajdos-Torok, M. (1964). Nouv. Rev. franc. Hèmat., 4, 575.

Haeger-Aronsen, B. (1962). Lancet, 1, 1073.

(1963). Amer. J. Med., 35, 450.

Harber, L. C., Fleischer, A. S., and Baer, R. L., (1964). J. Amer. med. Ass., 189, 191.

Holti, G., Magnus, A. I., and Rimington, C. (1963). Brit. J. Derm., $75,225$.

Porter, F. S., and Lowe B. A. (1963). Blood, 22, 521.

Redeker, A. G., and Berke, M., (1962). Arch. Derm., 86, 569.

, and Bryan, H. G. (1964). Lancet, 1, 1449.

Rimington, C., and Cripps, D. J. (1965). Ibid., 1, 624. 